Resumo de Tese

\title{
A OBSERVAÇAO SISTEMATIZADA NA IDENTIFICAÇÃO DOS PROBLEMAS DE ENFERMAGEM EM SEUS ASPECTOS FÍSICOS *
}

\author{
Dra. Wanda de Aguiar Horta **
}

\section{INTRODUÇÃO}

O desenvolvimento científico, sócio-econômico, o reconhecimento da saúde como valor econômico e outros fatores levaram a enfermagem a reformular seus conceitos e assumir maior responsabilidade perante a sociedade.

A enfermagem profisisonal, a partir de 1860, atravessou várias fa.ses evolutivas, já bem caracterizadas, e no momento se defronta com a pesquisa das bases cientificas de seus procedimentos. Surge a questão: como cuidar científica e eficientemente do paciente, permitindo que ele se recupere rapidamente?

Tentando solucionar o problema a enfermagem vem adotando um método próprio de ação junto ao paciente: identificar os seus problemas para chegar ao diagnóstico de enfermagem e então traçar um plano de cuidados que atenda especificamente às necessidades do indivíduo considerado.

Este processo baseia-se no método científico, sendo o seu primeiro passo a observação atenta para o levantamento de dados significativos para a enfermagem.

A metodologia sistematizada de observação, já preconizada por Florence Nightingale e considerada como uma das responsabiliciades legais profissionais do enfermeiro, por Lesnik, não tem sido

* Resumo da tese apresentada para conquista do grau de doutor, outubro, 1968.

** Professor Livre Docente do Departamento de Enfermagem Médico Cirúrgica da Escola de Enfermagem da Universidade de São Paulo. 
entretanto objeto de ensino e aplicação na profissão onde todas as condições levam ao favorecimento da observação acurada e planejada.

\section{APRESENTAÇÃO DO PROBLEMA}

Como observar o paciente de maneira sistemática, científica e eficiente para identificar os problemas que nos levarão posteriormente ao diagnóstico de enfermagem?

Este estudo limita-se a apresentar um método para observação dos aspectos físicos dos problemas de enfermagem do paciente, considerando entretanto a conexão entre os problemas físicos, os psicosociais e espirituais.

\section{OBJETIVO}

Introduzir na prática de enfermagem a técnica de observação sistematizada do paciente, como processo para identificar os aspectos físicos dos problemas de enfermagem por ele apresentados.

\section{METODOLOGIA}

Fundamenta-se, em suas linhas gerais, no exame físico usado pelo médico; difere, entretanto, fundamentalmente no que diz respeito a objetivos e em sua orientação geral.

O estudo realizou-se em hospital geral, campo de ensino, tendo sido examinados 50 pacientes, 25 homens e 25 mulheres, adultos, internados em unidades de Clínica Médica e Cirúrgica. A amostragem foi ao acaso.

Elaborou-se uma ficha de observação constando de sete partes distintas.

I - Identificação, data, nome, idade, sexo, cor, ocupação, estado civil, filhos, grau de instrução, religião, nacionalidade, naturalidade, procedência, diagnóstico médico, número de internação.

II - Condições gerais: Vestuário, estado mental, expressão facial, estado de nutrição, peso, altura, postura e locomoção, hábitos (fumo, álcool, drogras), alergias.

III - Sinais Vitais: Valores, frequência e características de temperatura axilar, pulso apical e radial, respiração e pressão arterial.

IV - Condições dos segmentos, sub-divididos em: cabeça e pescoço, membros superiores e inferiores e tronco. Em cada segmento foram observados: condições de limpeza, lesões, secreções, cor, for- 
ma, uso de cosméticos, acuidade dos órgãos dos sentidos, obstruções, motilidade, odor, falta de parte de segmentos (dentes, falanges, etc.), distribuição de pelos, estado dos músculos e veias para medicação parenteral, condições de unhas e sola dos pés, coluna vertebral, genitais externos, mamas e anus.

V - Condições específicas relacionadas: à pele em geral. aparelho locomotor, tonus muscular, funcionalidade do sistema digestivo, respiratório, circulatório, uro-genital, repouso, sono, exercícios.

VI - Queixas do paciente: resumo de suas queixas.

VII - Conclusões, problemas identificados.

Procedimento - Os pacientes foram examinados por ocasião de sua admissão ao hospital, antes de serem atendidos pela equipe de enfermagem da sala de admissão, unidade de trabalho subordinada à Sub-divisão de Enfermagem do Hospital em estudo.

Instrumental utilizado - Ficha de observação, caneta, balança clínica com antropâmetro, termômetro, esfigmomanômetro e estetoscópio, relógio com ponteiro de segundos, espátula de madeira, garrote, bolas de algodão embebidas em partes iguais de álcool e éter, mesa de exame, lençois, biombos.

Técnicas utilizadas - Preparo do paciente, ambiente, entrevista exame físico por meio de inspeção, palpação e ausculta (presssão arterial e pulso apical).

Determinaram-se critérios para classificar a normalidade de valores, condições de limpeza, postura, escaras, sono, tosse e outros.

Os pacientes observados foram acompanhados da admissão até a alta ou óbito, num prazo limite de 50 dias, o que nos levou à redução dos pacientes observados a 46 , pois 4 pacientes não tiveram alta no período pré-estabelecido. O acompanhamento foi executado da seguinte maneira: segunda observação completa 24 horas após a. admissão, as subsequentes cada quarenta e oito horas no préoperatório e em pacientes em bom estado geral; cada 24 horas no pós-operatório ou agravamento do estado geral e cada 12 horas nos nos pacientes graves. Todos os pacientes eram visitados diariamente.

As observações coletadas por esta técnica foram comparadas àquelas anotadas pela equipe de enfermagem nos relatórios de enfermagem, dentro da rotina normal hospitalar.

Foram identificados 2184 problemas, média de 47,5 por paciente, sendo que os pacientes analfabetos e semi-analfabetos apresentaram média de 46,2 enquanto os alfabetizados, 46,6. A maioria dos problemas destes pacientes estavam relacionados à limpeza corporal.

Foram efetuadas 524 observações, em média de 11,4 para 15,4 dias de hospitalização. 
As pacientes do sexo feminino, e os pacientes de ambos os sexos solteiros e viúvos apresentaram maior média de problemas.

Os problemas encontrados foram definidos e identificados pela análise de cada ficha de observação daí resultando 167 problemas gerais. Estes por sua vez constituíram 12 grandes áreas de problemas correlatos. Cada problema apresentado foi tabulado uma única vez por paciente, mesmo que houvesse repetição.

Apresentam-se a seguir as áreas com o número de problemas identificados pela observação sistematizada e pela observação do serviço de enfermagem hospitalar em números absolutos e percentuais.

\begin{tabular}{|c|c|c|c|c|}
\hline \multirow{2}{*}{$\begin{array}{l}\text { Problemas } \\
\text { relacionados à }\end{array}$} & \multicolumn{2}{|c|}{$\begin{array}{l}\text { Observação Sis- } \\
\text { tematizada }(\%)\end{array}$} & \multicolumn{2}{|c|}{$\begin{array}{c}\text { Observação } \\
\text { dos serviços } \\
\text { de enfermagem } \\
\text { hospitalar }(\%)\end{array}$} \\
\hline & 213 & $(9,8)$ & 57 & $(8,6)$ \\
\hline $\begin{array}{l}\text { Limpeza corporal } \\
\text { lomocotor }\end{array}$ & 126 & $(5,8)$ & 1 & $(0,1)$ \\
\hline $\begin{array}{l}\text { Locomoção e aparelho } \\
\text { locomotor }\end{array}$ & 126 & $(5,9)$ & 16 & $(2,4)$ \\
\hline Revestimento cutâneo-mucoso & 429 & $(19,6)$ & 83 & $(13,3)$ \\
\hline Temperatura corporal & 88 & $(4,0)$ & 56 & $(8,5)$ \\
\hline Aparelho cárdio-respiratório & 349 & $(16,0)$ & 152 & $(23,0)$ \\
\hline Sistema digestivo & 335 & $(15,4)$ & 118 & $(17,7)$ \\
\hline Aparelho uro-genital & 62 & $(2,8)$ & 30 & $(4,5)$ \\
\hline Orgãos dos sentidos & 80 & $(3,7)$ & 4 & $(0,6)$ \\
\hline Sono & 62 & $(2,8)$ & 20 & $(3,0)$ \\
\hline $\begin{array}{l}\text { Aplicação de medicação } \\
\text { parenteral }\end{array}$ & 83 & $(3,8)$ & 25 & $(3,8)$ \\
\hline \multirow[t]{2}{*}{ Queixas do paciente } & 227 & $(10,4)$ & 95 & $(14,4)$ \\
\hline & 2184 & $(100,0)$ & 662 & $(100,0)$ \\
\hline
\end{tabular}

Na análise dos resultados encontrou-se ter havido maior aproximação, relativamente aos mesmos problemas identificados pela observação sistematizada e a de rotina, nos grupos relacionados à temperatura corporal, urogenital, aparelho cárdio-respiratório e queixa do paciente. Na admissão o Serviço de Enfermagem só ident1ficou problemas nas áreas cárdio-respiratórias, digestiva e de temperatura corporal. Nenhum problema foi identificado nas demais áreas.

Estes resultados vêm evidenciar que a enfermagem hospitalar encontra-se voltada ainda para os cuidados clínicos (ordens mé- 
dicas) dos pacientes, pois aqueles problemas identificados se referiam principalmente à verificaçăo dos sinais vitais, controle de diurese, curativos, sonda vesical, venóclise, oxigênio-terapia, jejum, sonda naso-gástrica, controle de vômitos e evacuações e à queixas dos pacientes relacionadas às dores.

Poucos foram os problemas identificados em áreas que dizem respeito diretamente às funções específicas de enfermagem, tais como condições de limpeza corporal, condições dos locais para medição parenteral, cuidados com o revestimento cutâneo-mucoso, órgãos dos sentidos, condições gerais do paciente, de sua locomoção e motricidade, sono e repouso.

$\mathrm{Na}$ admissão do paciente no hospital, pela observação sistematizada, identificou-se 1034 problemas, $43,7 \%$ do total enquanto que a equipe de enfermagem da Sala de Admissão somente identificou 76 cu seja $11,5 \%$.

Foi possível ainda estabelecer a periodicidade das observações. Assim é que os pacientes em bom estado geral e pré-operatório apresentaram média de 0,8 problemas cada 48 horas; os pacientes em pós-operatório apresentaram média de 3,5 problemas por 24 horas; os casos graves apresentaram média de 2,8 problemas cada 24 horas, e os dois pacientes que faleceram e foram observados cada 12 horas, apresentaram respectivamente, em cada periodo, de 2 a 5 problemas.

As visitas diárias permitiram detectar problemas que demonstraram, entre outros fatos, agravamento do estado do paciente, presença de intercorrências como resfriados, odontalgias, crises hipertensivas, hipertermia, hiperglicemia, complicações pós-operatórias.

Observou-se ainda ao que diz respeito às observações anotadas pelo Serviço de Efermagem, que em 28 dos pacientes, cujas anotações foram feitas por auxiliares de enfermagem e atendentes, a média de problemas anotados foi de 8,7. Os demais 18 pacientes tiveram, além de observações registradas por auxiliares, atendentes, (15) por estudantes de enfermagem num periodo de um a 15 dias, (3) por enfermeiros durante dois a quatro dias na sala de recuperação cardíaca e um que foi cuidado durante toda a sua internação, oito horas por dia por uma parente enfermeira. Apesar disso. a média de problemas identificados nas anotações foi 23,3 inferior à nossa média de 47,5.

\section{CONCLUSÕES}

A observação sistematizada permitiu identificar 2184 problemas em 46 pacientes, em contraposição aos problemas anotados pelo pessoal de enfermagem que foi de 662 problemas, isto é, 30,3\% dos 
identificados pela sistematização. Na admissão do paciente é possível identificar $47,4 \%$ dos problemas, sendo estes refrentes principalmente à limpeza corporal, condições gerais, locomoção e aparelho locomotor, órgãos dos sentidos e condições dos segmentos para medicação parenteral. A visita diária ao paciente é indispensável para a identificação de novos problemas. Para a identificação de problemas físicos, a observação completa cada 48 horas foi suficiente e, em pacientes graves e no pós-operatória, esta se torna indispensável cada24 ou 12 horas.

Os enfermeiros de cabeceira registram os problemas de enfermagem de seus pacientes dentro das limitações de seu preparo para esta função, o mesmo ocorrendo com os estudantes de enfermagem. As enfermeiras em cargos de chefia delegam ao pessoal auxiliar, sem orientação e supervisão adequada, a função de observar e atender às necessidades dos pacientes, daí resultando baixo nível de identificação de problemas, e, por conseguinte, baixo nível de cuidados de enfermagem. 